\title{
DEIXA ELA ENTRAR: A REALIDADE COMO INQUIETAÇÃO NO FANTÁSTICO
}

\author{
Adrianna Alberti ${ }^{1}$ \\ Fabio Dobashi Furuzato²
}

\begin{abstract}
RESUMO: A literatura fantástica abarca muitas obras de forma confusa, pois comumente definese a narrativa fantástica como aquilo que não é real, ou seja, fantástico, irreal, fantasia, porém, não se trata apenas de uma narrativa cujo aparecimento de elemento sobrenatural é definidor. Partimos do estudo das contribuições teóricas de Tzvetan Todorov, presentes em sua obra Introdução à literatura fantástica (2008) que, através de abordagem mais estruturalista, estabelece parâmetros rígidos sobre o fantástico, sendo este delimitado a partir da incerteza e da hesitação. Em diálogo, tomamos a teorização do fantástico de David Roas, em $A$ ameaça do fantástico: aproximações teóricas (2014), que indica o fantástico a partir da relação conflituosa entre a obra literária e o real, tal qual o leitor o compreende e percebe, sendo, dessa forma, o fantástico tido como a representação da transgressão do real. Elaboramos então, a análise do elemento vampiro, aplicado na obra contemporânea Deixa ela entrar (2014), de John Ajvide Lindqvist.
\end{abstract}

PALAVRAS-CHAVE: Literatura fantástica. Tzvetan Todorov. David Roas.

\section{UMA INTRODUÇÃO AO ESTUDO FANTÁSTICO}

Propomos-nos a analisar o campo da literatura denominada literatura fantástica e suas características a partir da análise da representação de um dos elementos sobrenaturais conhecidos do fantástico: o vampiro, através da obra Deixa ela entrar (2014), de John Ajvide Lindqvist.

Surgida entre os séculos XVIII e XIX, influenciada pelo romantismo e pelo gótico, a narrativa fantástica, como a conhecemos, comumente mescla elementos de terror, horror e medo. Porém, por uma se tratar de uma produção ficcional vasta, em que a principal característica é o rompimento da realidade diegética da obra com o surgimento de seres ou elementos sobrenaturais, ou seja, pelo aparecimento de fenômenos que não condizem com a realidade, abarca muitas obras de forma confusa.

Comumente o que ocorre é a generalização do que se considera fantástico que torna-se mais sinônimo daquilo que não é real, ou seja, irreal, ficcional, imaginário. $O$ termo traz à mente outros conceitos que, igualmente remetem ao que não é verdadeiro, como por exemplo, definições como

\footnotetext{
1 Graduada em Psicologia pela Universidade Federal de Mato Grosso do Sul, UFMS. Email: adrianna.alberti@gmail.com

2 Professor Doutor em Teoria e História Literária pela Universidade Estadual de Campinas, UNICAMP. Email: fabiodf71@yahoo.com.br
} 
extraordinário, fora do normal, fantasia e mesmo imaginação.

Foram os estudos de Tzvetan Todorov, na década de 1970, que possibilitaram a sistematização e estabelecimento de rigor teórico ao campo literário, tendo estabelecido o fantástico como um gênero entre gêneros, aproximando-o do gênero maravilhoso e do gênero estranho. Através de método estruturalista, Todorov "tenta explicar o fantástico a partir do interior da obra, a partir de seu funcionamento. Sua intenção, em ultima instância, é elaborar uma caracterização formal do gênero fantástico" (ROAS, 2014, p. 40).

O teórico busca definir um gênero literário, sistematizando tanto os procedimentos narrativos quanto seus temas. $O$ fantástico é apresentado a partir da hesitação que a narrativa causa. Quando a obra opta por uma explicação, seja ilusão ou verdade, o fantástico perde sua característica e a obra deve ser considerada referente ou ao gênero do estranho ou ao gênero do maravilhoso.

Para tanto sua classificação dependerá de qual justificativa a obra dará ao elemento fantástico: o gênero maravilhoso é considerado como aquele em que o sobrenatural é aceito como real, sem questionamentos ou hesitações; e o estranho é aquele em que seu conteúdo sobrenatural, em geral, explicado, é a forma como o autor dá continuidade à sua história, a obra é rotulada como pertencente a um ou outro gênero (TODOROV, 2008).

Não se trata apenas de uma aparição de um elemento sobrenatural que rompe a realidade, não é o surgimento do sobrenatural que define o gênero fantástico. Em outras palavras, o fantástico não pode ser definido apenas como oposto ao real, aqui entra em discussão a questão do fantástico como hesitação, com a possibilidade de ser situada entre o real e o imaginário, entre o real e a descrença do fenômeno acontecido, surgindo também, a possibilidade da loucura.

No espírito do fantástico "é a hesitação que Ihe dá vida" (TODOROV, 2008, p. 38). Deve-se manter o sentimento de inquietação, a dúvida é o essencial.

Todorov indica duas categorias temáticas distintas e restritivas: os temas do eu, que se caracterizam pelo limite entre matéria e espírito, entre o psíquico e o físico, que ao ser ultrapassado pelo surgimento do sobrenatural, perde a identificação e a diferenciação entre o mundo exterior e o eu, modificando assim, a percepção de tempo e espaço.

E os temas do tu, que são designados por seu caráter sexual, trazendo à 
tona questões da sexualidade humana que normalmente são ocultadas. É a própria obra que dará sentido aos elementos do texto, Todorov (2008) evita analisar os temas e seus elementos detidamente, por justamente apontar que cada obra dará o sentido desejado a essas características.

Assim, aos temas do eu ligam-se os domínios do olhar, como óculos, espelhos, lunetas. O universo da infância, cujo "acontecimento essencial que provoca a passagem da primeira organização mental a maturidade (através de uma série de estádios intermediários) é a chegada da linguagem" (TODOROV, 2008, p. 154), ou seja, o surgimento da linguagem significa e altera a percepção do mundo. Também possui ligação aos temas do eu, em analogia, o mundo das drogas, em que por se tratar "de novo mundo de um mundo sem linguagem: a droga se recusa à verbalização" (TODOROV, 2008, p. 155). Similar às psicoses, em que também trata-se de um mundo sem uma explicação ordenada, "somos levados a nos apoiar em descrições (do mundo psicótico) feitas a partir do universo do homem 'normal'” (TODOROV, 2008, p.155).

Todorov (2008) sobre os temas do $t u$, remete histórias que dizem respeito à satisfação de sentimentos e sentidos internos e, especialmente, o desejo sexual sentido com relação à punição ou pecaminoso, consequentemente errado socialmente, caracterizando aqui o estranhamento social desperto por essas situações distintas. $O$ amor intenso e as transformações do desejo também estão ligados aos temas do tu. O fantástico fala de ocasiões como incesto, homossexualidade, relações não monogâmicas, sadismo, amores crueis, desejo pela morte (a necrofilia representada por vampiros ou mortos que retornam para vida).

A partir de Todorov, diferentes autores passaram a falar sobre literatura fantástica, alguns em uma espécie de complementação das ideias desenvolvidas por ele, e outros criticando e oferecendo uma nova roupagem à teoria do fantástico.

David Roas, teórico mais contemporâneo, em seu trabalho $A$ ameaça do fantástico: aproximações teóricas (2014) tenta abarcar o funcionamento, o sentido e o efeito do fantástico e tem a literatura fantástica como fenômeno de expressão humana. Para o teórico, o fantástico é uma categoria estética multidisciplinar, não se restringindo apenas ao campo literário, mas podendo ser encontrado também 
no cinema, nos jogos, e em outras formas da expressão humana.

Sua teoria é embasada em quatro concepções: a realidade, o impossível, o medo e a linguagem:

[...] sobre o fantástico: sua relação necessária com a ideia do real (e, portanto, do possível e do impossível), seus limites (e as formas que habitam aí, como o maravilhoso, o realismo mágico ou o grotesco), seus efeitos emocionais e psicológicos sobre o receptor, e a transgressão que supõe para a linguagem a vontade de expressar o que, por definição, é inexpressável (ROAS, 2014, p. 8).

O gênero fantástico "começa a desenvolver-se em uma época marcada pela ideia de um universo estável ordenado [...] nesse sentido, o fantástico definese pela transgressão a essas regras" (CAMARANI, 2014, p. 166). "[...] Imerso num mundo povoado de convencionalismos e banalidades, que o levam à constatação de sua insignificância diante do que não consegue explicar satisfatoriamente para si mesmo" (ALVAREZ, 2014, p. 21). O fantástico tem o propósito de desestabilizar os limites e a validade da forma como se percebe 0 real a partir da experimentação da inquietação pela falta de sentido, ou pela inquietação da falta de sentido do real.

Sem o sobrenatural o fantástico não pode existir, porém, o fator obrigatório, de acordo com Roas (2014), para a literatura fantástica é a transgressão das leis do mundo real, ou seja, o sobrenatural é aquilo que transgride as leis do real. "a narrativa fantástica põe o leitor diante do sobrenatural, [...] para interrogá-lo e fazê-lo perder a segurança diante do mundo real" (ROAS, 2014, p. 31). O fantástico obtém sucesso ao provocar no leitor a incerteza de sua percepção do real, e consequentemente da percepção de sua própria existência.

Para alcançar essa transgressão, o contexto sociocultural é importante para a experiência do fantástico, visto que, "toda representação da realidade depende do modelo de mundo de que uma cultura parte" (ROAS, 2014, p. 39). É aquilo que se conhece por real que norteará a leitura da obra, consequentemente, o efeito de conflito do fantástico depende do quadro de referência do leitor.

"E diretamente ligado a essa transgressão, a essa ameaça, aparece outro efeito fundamental do fantástico: o medo" (ROAS, 2014, p135 - grifo do autor). A inquietude, a estranheza, a angústia e outros sentimentos similares são 
alcançados com o sentimento de ameaça que surge no leitor, ainda que o medo não seja elemento exclusivo e nem obrigatório do fantástico.

Há necessidade do realismo para se alcançar com o êxito o conflito entre o real e o sobrenatural, ou seja, a narrativa fantástica exige técnicas realistas. A verossimilhança com a realidade fora da obra é que oferecerá ao leitor o palco desse conflito.

A narrativa fantástica supera os limites da linguagem, pois, sendo o fenômeno fantástico impossível de explicar, o escritor fala daquilo ainda não dito. "O autor fantástico deve obrigá-las [as palavras] durante certo momento, a produzir um 'ainda não dito', a significar um indesignável” (ROAS, 2014, p. 170 grifos do autor). No entanto, não há recursos e procedimentos linguísticos que sejam exclusivos do fantástico, há uma forma de utilizar os recursos da linguagem para fazer o efeito do fantástico.

Ao contrário do que Todorov postula, que o fantástico havia perdido sua função social com o advento da Psicanálise, por tratar de temas antes considerados tabus, para Roas (2014) o fantástico permanece existindo. O fantástico problematiza os limites entre real e irreal, sem apagar suas fronteiras, diferentemente de narrativas pós-modernas e surrealistas.

\section{A REPRESENTAÇÃO DO VAMPIRO}

Dentro desse vasto universo de temas e personagens do fantástico existem seres que se destacam devido sua fama, nesse sentido, optamos para análise o elemento sobrenatural do vampiro.

Assim como o fantástico em si, o vampiro é outro conceito que costuma confundir e abarcar diferentes ideias. Peguemos uma concepção popular de vampiro: "Vampiro: vam-pi-ro. sm. 1. Ente fantástico que, segundo a crendice popular, ergue-se das sepulturas para sugar o sangue dos vivos" (MICHAELIS, 2016, s/p.). Júnior (2009) nos aponta que a palavra vampiro tem origem do vampir sérvio e do upyr de origem russa, e segundo o autor, Melton em sua obra Enciclopédia dos Vampiros (2008), aponta o vampiro como um cadáver reavivado, que suga o sangue dos vivos (a energia vital) para manter-se vivo (um morto-vivo). 
O vampiro era inicialmente relacionado a criaturas sobrenaturais, normalmente seres demoníacos e entidades espirituais, e seu mito é observado em relatos em diferentes lugares, a Lâmia da mitologia grega, Langsuyar na Malásia, Lilith na mitologia judaica (JUNIOR, 2009).

Nos estudos literários, as teorias (principalmente as anteriores a Todorov) resumiam-se a categorizar ou indicar a existência de contos e histórias com vampiros e que estas seriam fantásticas. Para Caillois os vampiros eram considerados como "os mortos que conservam uma perpétua juventude sugando o sangue dos vivos" (TODOROV, 2008, p. 109).

Mas é Todorov quem crítica este tratamento de agrupamento temático, para ele "classificar todos os vampiros juntos, por exemplo, implica que o vampiro signifique sempre a mesma coisa, qualquer que seja o contexto em que apareça" (2008, p. 110).

Em nosso mundo (real) não existem tais criaturas, não há diabos, nem sílfides, nem vampiros, e que estes estão entre os elementos de um acontecimento impossível que nossas leis não podem explicar, e que, é apenas com a linguagem que tal acontecimento pode existir, "o sobrenatural nasce na linguagem" (2008, p. 90).

Isso é importante, pois, para o teórico a obra é como um todo coerente e estruturado, em que cada elemento não se articula fora da relação com os outros elementos, portanto, o sentido da obra está na obra, e não fora dela.

Todorov (2008) elabora sua classificação a partir de temas, e aqui o vampiro insere-se aos temas do $t u$, aqueles que tratam dos desejos proibidos e tabus não aceitos socialmente. Dessa forma ao falar sobre o desejo que passa pela crueldade, o teórico para no tema da morte, que se estabelece a partir de uma relação entre medo e amor e como variante do desejo (amor) pela morte, encontra-se o desejo voltado ao corpo (cadáver), que leva à necrofilia.

Na literatura fantástica, a necrofilia assume habitualmente a forma de um amor com vampiros ou com mortos que voltam ao meio dos vivos. Esta relação pode de novo ser apresentada como a punição a um desejo sexual excessivo; mas ela pode também não receber uma valorização negativa (TODOROV, 2008, p.145-146).

Faz-se necessário lembrar que Todorov busca assinalar a existência do tema, não interpretá-lo. O que o teórico faz é sobrepor termos abstratos, como 
sexualidade, morte e termos concretos, como lobisomem e vampiro, porém, sem desejar estabelecer de forma definitiva uma relação de significação entre os termos, mas sim, uma compatibilidade entre eles.

Por outro lado, temos o espanhol David Roas que nos aponta que a partir da relação de conflito entre a ideia de real existente e do impossível que se dá o fantástico. Esse conflito, longe de ser estanque, desenvolve-se de acordo com a concepção coletiva de real. E, dentre os elementos conhecidos da literatura fantástica, os monstros se destacam por serem, normalmente, os principais personagens na narrativa.

Segundo Roas (2014), em palestra proferida em evento na UERJ, a cujo texto tivemos acesso, o monstro encarna os nossos medos ancestrais (como o medo da morte e do desconhecido), apontando para uma questão importante em relação à literatura fantástica, que nos auxilia a compreender melhor a forma como o ser humano elabora a representação subjetiva de seus medos na literatura. Os monstros são a representação da transgressão e da desordem, sendo antinaturais tanto do ponto de vista físico, como do psicológico. Nesse sentido, eles são paradoxais: impossíveis de ser. Através do discurso fantástico, trazem à luz aquilo que é proibido, que na mente foi reprimido. E tal conteúdo, por estar socialmente estabelecido (em uma dada época histórica, sob o viés do pensamento vigente), explica o motivo da presença e das funções do monstro fantástico se atualizarem (ROAS, 2014).

Em sua obra A Ameaça do Fantástico: aproximações teóricas (2014), ainda tratando sobre o recurso fantástico no cinema, ele aponta que o vampiro é uma figura transgressora devido a sua natureza impossível. Essa diferença de acepção sobre o elemento fantástico modifica sua interpretação, ao passo que Roas não se debruça a estabelecer temas ou personagens específicos do fantástico, sua compreensão do monstro é mais abrangente.

Para elucidar essa diferença peguemos uma obra considerada clássica quando nos referimos a vampiros: Drácula de Bram Stoker. A narrativa foi originalmente escrita em 1897 e nos traz a história do personagem que ainda hoje inspira muitas outras obras artísticas e literárias. Inspirado em Vlad Tepes regente da Wallachia, atual Romênia, conhecido por sua crueldade para com os inimigos vencidos, como o empalamento de centenas de pessoas (JUNIOR, 2009). 
A história se inicia com Jonathan Harker sendo enviado à Transilvânia tratar da aquisição de propriedades inglesas por Conde Drácula, quando o vampiro começa a fazer vítimas na Inglaterra o Dr. Van Helsing é chamado para ajudar, culminando na perseguição e morte de Drácula. A hesitação e o mistério perpassam a obra. Como no seguinte trecho:

Como aquele estranho homem retornou à caleça é algo que eu nunca saberei explicar. $O$ fato é que eu o ouvi erguer a voz num tom de comando imperioso, e, virando-me na direção desse som, o vi parado e de pé no meio da estrada. Ele agitou seus longos braços - dando-me a impressão de que se desvencilhava de um obstáculo incorpóreo -, e os lobos retraíram, recuando cada vez mais. Então, outra pesada nuvem voltou a encobri a lua, devolvendo-nos à plena escuridão (STOKER, 2002, p. 21).

É o teórico espanhol que nos fala mais detidamente sobre esta obra:

Drácula (1897), ambientada em uma Inglaterra vitoriana retratada em todos os seus detalhes, onde só aparece um elemento impossível, o vampiro, que irrompe em tal realidade provocando sua ruptura. Como evidencia o romance de Stoker, o vampiro (e qualquer fenômeno sobrenatural) para seu devido funcionamento fantástico, deve ser sempre entendido como exceção, do contrário se converteria em algo normal, cotidiano, e não seria tomado como uma ameaça (não estou falando aqui, evidentemente, da ameaça física que o vampiro representa em suas vítimas), como uma transgressão das leis que organizam a realidade. (ROAS, 2014, p.42-43).

O vampiro, na obra de Stoker, apresenta uma série de características, que tornam o elemento sobrenatural. Drácula possui força sobre humana, transforma seu corpo, como em lobo e em morcego, mas também em névoa, é capaz de andar pelas paredes, hipnotiza pessoas, é eterno e não envelhece, possui alto poder de regeneração de seu corpo, sua imagem não é refletida em espelhos. Para sobreviver alimenta-se de sangue e para transformar suas vítimas em vampiros, ele precisar dar o seu sangue para o outro. Para ferí-lo utiliza-se símbolos sagrados, como a cruz, e para matá-lo é necessária uma estaca de madeira ser cravada em seu coração, a luz do sol também é fatal para o vampiro. Há uma forte conotação sexual envolto no personagem vampírico, sendo a sedução uma forte característica das personagens sobrenaturais.

Para Roas (2014) se o monstro (o vampiro) irrompe como impossível em uma realidade verossímil transgredindo as leis que organizam a compreensão do real, levando dessa forma a fazer o personagem e o leitor se questionarem, a obra pode ser considerada fantástica. Todorov (2008), por outro lado, parte de 
uma hesitação constante e sem justificativa final para que isso ocorra.

Concordamos com Roas quando este afirma "a vacilação não pode ser aceita como único traço definitivo do gênero fantástico, pois não comporta todas as narrativas que costumam ser classificadas assim" (2014, p. 43 - grifo nosso).

\section{DEIXA ELA ENTRAR}

Nosso objeto de estudo, a obra Deixa ela entrar (2014), do sueco John Ajvide Lindqvist, apresenta a história de Oskar. O garoto de doze anos vive no subúrbio de Estocolmo com a mãe separada do pai (considerado pelo menino como um bêbado e alguém muito emocional).

A trama nos apresenta o ponto de vista de diferentes grupos de personagens e suas vidas, elementos que se unem aos poucos na história, dando-Ihe sentido e continuação, porém, a narrativa nos traz especialmente, o desenvolvimento do personagem principal e de sua relação com o mundo, mais detidamente em sua relação com sua vizinha Eli, que descobrimos com a leitura, se tratar de um vampiro.

Oskar é um estudante comum, apesar do apreço e da curiosidade por serial killers, além de cometer pequenos furtos em uma loja de doce. Apresentado como um personagem tímido e medroso, que usa uma bola de esponja nas calças para segurar a urina, é alvo de bullying na escola por garotos de sua classe, maiores e mais fortes que ele, que o chamam de porco e como método de humilhação, além de bater, costumam pedir para que ele grite feito um. A violência que sofre é característica forte na trama, como podemos ver no trecho a seguir:

[...] Não, Tomas era mais sacana, mas quase nunca participava quando havia socos e arranhões. Esperto demais para isso. Provavelmente estava puxando o saco do policial agora. Se a Bola de Mijo fosse descoberta, seria Tomas quem realmente se aproveitaria disso para humilhá-lo durante um bom tempo. Jonny e Micke dariam um soco e pronto [...]" (LINDQVIST, 2012, p. 18).

Oskar é constantemente perseguido por seus colegas de sala, o que gera ainda mais violência. Durante toda a obra, a relação conflituosa entre Oskar, Tomas, Jonny e Micke é marcada. Oskar alimenta a vontade de matar Jonny, inclusive treinando com uma faca em uma árvore, desejando poder esfaquear o 
garoto. Ao ter sua amizade com Eli correspondida, Oskar adquire mais coragem, chegando a negar ser humilhado pelos garotos, até finalmente conseguir revidar a ameaça, quando em um passeio na escola bate com um galho de madeira no ouvido de Jonny.

Essa situação gera ainda mais violência, indo desde Oskar queimando sua sala de aula (para queimar a carteira de Jonny em retaliação) até o irmão mais velho de Jonny, que já era envolvido com drogas, tentar assassinar Oskar, que finalmente é salvo por Eli que, por sua vez, mata Jonny, seu irmão e os colegas no local.

Simultaneamente o narrador nos traz histórias paralelas que, em princípio nos parece soltas, mas que do meio para o final da trama se conectam e nos dão um sentido maior da obra.

Assim, temos Hakan Bengtsson, um homem de quarenta e cinco anos, um dos personagens mais complexos e interessantes da trama. Antes um professor, o homem fora demitido por denúncias de pedofilia. Durante a trama, percebemos que sua vida, agora devotada a Eli, é um conflito entre a culpa e a aceitação de seus desejos.

A violência recorrente em toda a trama também é apresentada sem floreios. Hakan tivera sua casa incendiada quando as pessoas de sua cidade souberam de seus gostos sexuais, tendo todos os seus pertences queimandos. Eli o encontra em um momento degradante da vida do homem, alcoólatra, ao ponto de beber álcool de cozinha e solução para acne.

Vemos sua degradação nesse trecho: "A embriaguez deixava-o descuidado, ele passava a mão em menininhos, recebeu pancada, foi parar na polícia. Ficou na delegacia por três dias e vomitou o que tinha e o que não tinha no estômago. Foi solto. Continuou a beber" (LINDQVIST, 2012, p. 232). Eli o acolhe, e sem questionar o homem passa a servi-lo. A criatura sobrenatural, nesse ponto, seria a representação da satisfação de um desejo impossível tornado possível, visto que mesmo parecendo ter apenas doze anos, Eli já possui alguns séculos de vida.

O personagem controverso está presente em outro tema delicado: prostituição infantil. Em duas passagens, presencia a prostituição de garotos. $\mathrm{Na}$ primeira, ele se contenta em olhar, julgando toda a situação feia e ruim, sendo 
zombado por seus amigos por seus escrúpulos, ele já possuía fotos, filmes e revistas, mas a ação em si Ihe causara repulsa. Em uma segunda passagem, buscando fazer uma doação em dinheiro a uma criança qualquer de rua, na biblioteca pública da cidade, e cedendo ao seu desejo, Hakan busca um grupo de jovens que agencia outras na prostituição infantil:

\begin{abstract}
Ele olhou para o menino que comprara. Alugara. Será que garoto tomava algum tipo de droga? Provavelmente. Seu olhar estava ausente, sem foco. O menino estava encostado na porta a meio metro dele. Era tão baixo que Hakan não precisava levantar a cabeça para olhá-lo nos olhos (LINDQVIST, 2012, p. 54).
\end{abstract}

Este mesmo personagem ainda passa por mutilação e deformação facial. Ao ser pego em uma tentativa de assassinato, Hakan joga no próprio rosto ácido clorídrico, porém, não morre, sobrevivendo internado em um hospital, ao passo que a polícia continua a investigar seus crimes.

Após ser sugado por Eli, Hakan se transforma em um morto-vivo disforme e não consciente, é o responsável pela cena que interpretamos como uma tentativa de estupro. A personagem encontra Eli de vestido amarelo, em um porão, primeiro tenta se masturbar, ao entrarem em um embate e tendo desacordado Eli, tentao violentá-lo. Durante a narrativa vemos Hakan se transformar de um homem com desejos não aceitos socialmente, para uma criatura sobrenatural e culminar como um animal irracional, que se move apenas pelo instinto de satisfazer seus desejos. Estas cenas são retratadas de forma realista e a violência é um incomodo.

Sua cabeça era um recipiente de dor fulgente na hora que o corpo foi
dobrado com violência, atado como se fosse uma bola de pano, e Eli
achou que ainda estava tendo uma alucinação de dor, pois, quando os
olhos começaram a enxergar, ele apenas via tudo amarelo. E, atrás do
amarelo, um vulto enorme, agitado.
Em seguida veio o frio. Na pele fina no meio das suas nádegas,
esfregavam uma bola de gelo. Alguma coisa tentava, primeiro cutucando
de leve, em seguida empurrando com força, penetrar nele. Eli arfou; o
pano do vestido na frente do seu rosto voou com o sopro e ele viu.
Hakan em cima dele. O único olho fitava as nádegas abertas lá embaixo.
As mãos segurando apertando os pulsos de Eli. As pernas tinham sido
afastadas brutalmente de modo que os joelhos eram pressionados no
chão de cada lado dos ombros de Eli e, quando Hakan pressionou ainda
mais, Eli ouviu os tendões da parte traseira das coxas se rompendo igual
a cordas que foram esticadas. (LINDQVIST, 2012, p. 418)

Devemos destacar que é justamente a realidade, e não o elemento 
sobrenatural, que mais nos choca e nos traz à reflexão. O que a torna interessante e importante são os temas e forma como são abordados, de maneira bem realista, natural, sem floreios e crua. Lindqvist nos traz temas como bullying, pedofilia, assassinato, alcoolismo, prostituição infantil; e o autor não se preocupa com suavizar esses temas.

\section{DISCUSSÃO}

De pronto sabemos que Todorov (2008) não considera as narrativas contemporâneas como narrativa fantástica, visto que as mudanças sociais após a virada do século fazem as obras fugirem do objetivo fantástico: tornar público aqueles temas que de outra forma seriam considerados não aceitos. Para 0 teórico as narrativas do século $X X$ são diferentes das narrativas tidas como tradicionais (as que ele busca explicar durante todo seu estudo), justifica que "em primeiro lugar, o acontecimento estranho não aparece depois de uma série de indicações indiretas" (TODOROV, 2008, p. 179), o acontecimento sobrenatural é que dá o curso da narrativa, em geral, as obras contemporâneas passam a tornar a hesitação inútil.

A verossimilhança importante a ambos os teóricos com que trabalhamos aqui é bem marcante, "é necessário que o texto apresente um mundo o mais real possível que sirva de termo de comparação com o fenômeno sobrenatural, isto é, [...] o realismo se converte assim em uma necessidade estrutural de todo o texto fantástico" (ROAS, 2014, p. 51). Todorov (2008) aponta que o fantástico só ocorre quando há dúvida quando parte de uma realidade próxima à nossa, verossímil.

Ambos os autores apontam que o objetivo do fantástico é falar de conteúdos que de outra forma seriam ou impossíveis ou difíceis de se lidar. Mas sabemos que não se trata apenas de trazer à tona o que não pode ser dito, ou que não é facilmente aceito pela sociedade.

A partir daqui nossas análises apontam uma diferença interessante: ao passo que para Todorov (2008), a obra do sueco não se classificaria como fantástica, para Roas (2014) esta seria um exemplo interessante de como o fantástico alcança seu objetivo e melhor caracterização.

Observamos que, o vampiro nessa obra, é aceito como elemento e 
acontecimento fantástico, a dúvida não permanece nem para o personagem (ainda que para alguns permaneçam) nem para o leitor. Em um momento importante da história, Oskar tem uma espécie de esclarecimento e conclui que Eli é um vampiro:

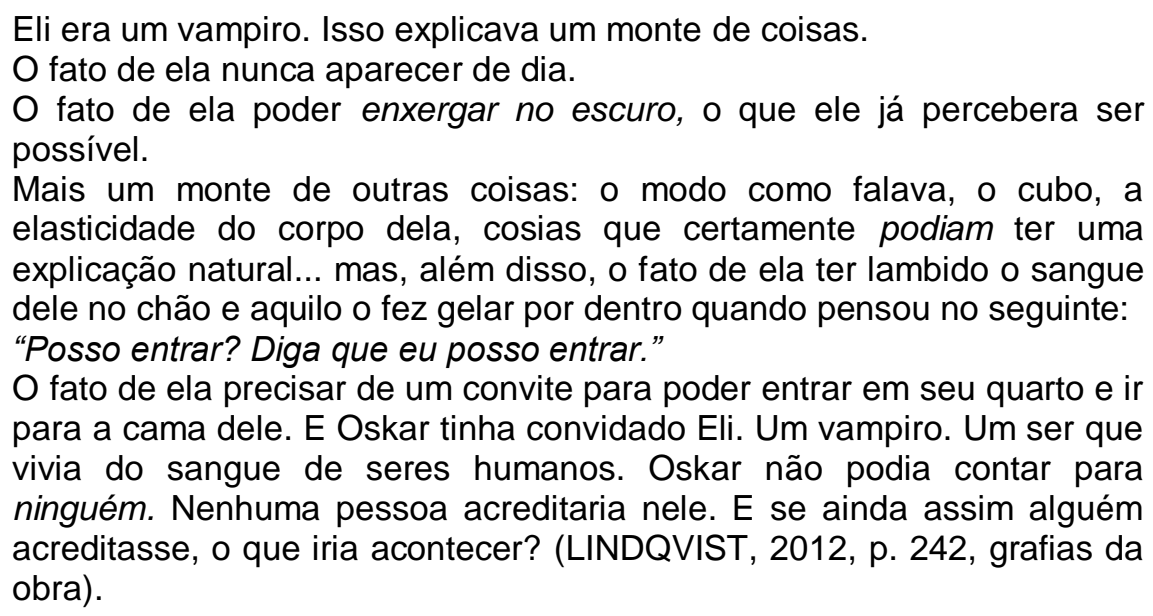

Mas o leitor já sabia que Eli era um ser sobrenatural antes de Oskar acreditar e chegar a essa conclusão, já havíamos lido Eli manifestar seus poderes e principalmente suas habilidades vampíricas ao se alimentar de um dos personagens da história.

Se a hesitação sem uma justificativa (científica ou sobrenatural) não se mantém, de acordo com Todorov (2008), a obra não é fantástica, mas sim fantástica-maravilhosa, ou maravilhosa apenas. Enquanto para Roas (2014), havendo essa transgressão da realidade como conhecemos, esse conflito entre 0 que se compreende e se percebe e faz tanto o personagem como o leitor questionar-se sobre o real, a obra alcança seu objetivo. O fantástico é alcançado por justamente seus elementos reais e verossímeis.

A inquietação é frente à realidade exposta. Oskar é um adolescente que descobre o amor, e a própria sexualidade, em um contexto real, a periferia de uma capital na década de 80. Mas, ao invés de ser apenas uma história de amor com vampiros, vemos temas fortes, relevantes e poucos tratados na convenção do gênero fantástico. Ao contrário da hesitação sobrenatural, como nos restringe Todorov (2008), a dúvida na obra de Lindqvist (2012) ocorre pela inquietação diante dos temas realistas e cruelmente expostos, ainda que saibamos se tratar de uma história de vampiro.

A representação do vampiro apresenta-se na obra em Eli, que se trata de 
um vampiro cujas características podem ser enumeradas como: assexual (tendo perdido o sexo masculino ao se transformar); sem identificação de gênero (por diversos momentos Eli transita entre o gênero feminino e masculino, mesmo que tange à linguagem, Eli é "ela" e é "ele" em diferentes momentos); vida eterna (ou ao menos uma longevidade sem data para o fim); avesso à luz do sol, Eli se esconde no banheiro durante o dia, com janelas e frestas tampadas para evitar o contato com o sol; pode enxergar no escuro; alimenta-se única e exclusivamente de sangue; transfere o vampirismo a partir da mordida (se a vítima permanece viva, se transforma também); necessita de convite para entrar em ambientes (caso contrário, seus poros começam a transpirar sangue, além de imensa dor); pode ser considerado um predador, possuindo características de um animal quando com fome ou em contato com sangue.

Algumas dessas características podem ser encontradas em outras obras sobre vampiros, Drácula também não sobrevive à luz do sol, também possui vida eterna e não envelhece, alimenta-se de sangue. Mas nos interessa o sentido do vampiro que é dado pela obra sueca. Para Todorov (2008), conforme já comentamos, o vampiro pode estar conectado ao desejo e amor pela morte, voltado para o corpo (necrofilia). No entanto, o desejo que vemos expresso por Hakan, por exemplo, é a possibilidade de extravasar seu desejo pedófilo, não por um corpo morto, mas por um garoto (a aparência de Eli é andrógena), sem que a culpa Ihe recaia, ainda que, como podemos ler, esse amor não é recompensado na mesma intensidade. Por outro lado, para Oskar, Eli pode chegar a ser como uma inspiração, para que ele consiga enfrentar seus medos e as coisas que vive, quando revida a violência que sofre e atinge um dos garotos de sua escola com um galho de árvore, cortando-o, ou quando coloca fogo na sua sala de aula, nas carteiras de alguns dos garotos que fazem dele um alvo.

Disso, podemos concluir que não há um elemento que designe o vampiro, além daquela que Roas afirma em sua palestra:

[...] los monstruos son siempre antinaturales em relación al esquema cultural de la naturaliza, no encajan en él, lo violan. De esse modo, los monstruos fantásticos son fisicamente amennazadores, también lo son cognitivamente, pues amenazan el conocimiento comum: son imposibles. (2014, s/p).

Ou seja, os monstros, inclundo o vampiro na narrativa de análise, são 
violadores da realidade, são impossíveis de acontecer. Também em outro momento Roas (2014) aponta que os monstros possuem uma função dupla, que é encarnar os medos ancestrais (como a morte, o desconhecido) e ao mesmo tempo nos colocar frente ao desconhecido do próprio homem, seu lado e desejos obscuros.

Pois, somos apresentados aos desejos obscuros do homem nessa obra, observamos claramente o desejo de Hakan por Eli ser ameaçador, o homem rompe com sua limitação social e seus escrúpulos, ao se transformar em um animal irracional seu instinto é se satisfazer, finalmente.

Oskar alcança ao lado de Eli uma liberdade sonhada, livra-se dos garotos que Ihe faziam mal. Seu salvador e libertador, mata-os e ele pode, finalmente, viver sem a ameaça de monstros, que para ele, eram muito mais perigosos do que Eli.

\section{CONSIDERAÇÕES FINAIS}

É difícil delimitar a literatura fantástica de uma maneira única e definitiva, como pudemos notar ainda que as definições desse campo não destoem completamente, cada teórico a trabalha de uma forma distinta e consequentemente essa concepção irá delimitar quais obras sejam consideradas ou não como fantásticas.

Concordamos com Roas (2014) quando este aponta que a literatura fantástica é uma vasta produção literária que pode abarcar outras formas de expressão humana, como cinema, quadrinhos, desenhos, entre outras. Também concordamos quando ele aponta que o fantástico modificou-se com os adventos teóricos desenvolvidos pela sociedade, ou seja, que o que se considera em uma obra fantástica está em algum grau influenciado e conectado ao contexto sociocultural em que se está inserida a obra (seja ela escrita ou lida).

Já podemos concluir, baseando-nos nos estudos tanto de Todorov (2008) como Roas (2014), que a literatura fantástica não pressupõe um elemento sobrenatural ou fantástico por si só, somente a aparição de algo sobrenatural que foge das leis da realidade na narrativa não torna a obra uma literatura fantástica.

Enquanto para Todorov (2008) é necessário que a hesitação causada por 
esse elemento seja constante e procure-se manter até o final, caso contrário, se torna uma obra de gênero estranho ou de gênero maravilhoso (e suas nuances). Para Roas (2014) é necessário que tal situação faça a concepção e a relação com o real seja questionada, é mister haver uma transgressão e um consequente conflito.

A obra analisada indica justamente essa diferença entre um e outro teórico, Deixa ela entrar (LINDQVIST, 2012) pode ser considerada fantástica para Roas (2014), mas não poderia ser considerada fantástica para Todorov (2008), visto que a hesitação não se mantém, ainda que atenda a outras condições de classificação do teórico búlgaro.

É justamente os elementos realistas da obra que nos causa inquietação, o vampiro na obra tonifica e exponhe mais agressivamente essa realidade. A cena que interpretamos como uma tentativa de estupro se passa justamente pelos dois personagens sobrenaturais, em nossa análise, Hakan monstruoso pode ser interpretado facilmente como uma metáfora de um sujeito irracional, quando retomamos a cena da tentativa de estupro.

Ao retomarmos historicamente a narrativa fantástica, tal qual Roas (2014) nos apresenta, vemos que o fantástico passou por mudanças estruturais e formais ao longo do tempo, tendo adiquirido características inicialmente românticas e góticas, para depois aderir características de cotidianização e aproximação máxima do realismo, já no século $\mathrm{XX}$, trazendo ao quintal dos leitores os acontecimentos sobrenaturais.

Compreendemos quão impactante é o fantástico de Lindqvist, que ao trazer temas tão violentos e reais para o fantástico, vemos como o sobrenatural permite problematizar a ordem da nossa realidade, aquela que vivemos mais ou menos seguros e tranquilos. O mundo da narrativa fantástica, em qualquer tempo que seja escrita, é o nosso mundo.

\section{DEIXA ELA ENTRAR: REALITY AS A CARING IN THE FANTASTIC}

ABSTRACT: The fantastic literature encompasses many works in a confusing way, since the fantastic narrative is usually defined as that which is not real, that is, fantastic, unreal, fantasy, but it is not only a narrative whose appearance of supernatural element is definitive. We started from the study of the theoretical contributions of Tzvetan Todorov, present in his work Introduction to fantastic literature (2008), which, through a more structuralist approach, establishes rigid 
parameters about the fantastic, which is delimited from uncertainty and hesitation. In dialogue, we take the theorizing of David Roas's The fantastic threat: theoretical approaches (2014), which indicates the fantastic from the conflictual relationship between the literary and the real, as the reader understands and perceives it, being, in this way, the fantastic considered as the representation of the transgression of the real. We then elaborate the analysis of the vampire element, applied in the contemporary work Let It In (2014), by John Ajvide Lindqvist.

KEYWORDS: Fantastic literature. Tzvetan Todorov. David Roas.

\section{REFERÊNCIAS}

ALVAREZ, Roxana Guadalupe Herrera, Apresentação do Autor. In. ROAS, David, A ameaça do fantástico: aproximações teóricas. São Paulo: Unesp, 2014. 215p.

CAMARANI, Ana Luiza Silva, A literatura fantástica: caminhos teóricos. São Paulo, SP: Cultura Acadêmica, 2014. 217p.

JUNIOR, Pedro Augusto Moraes Simões, A Construção do Mito Vampiresco. In. $O$ Eterno Retorno de Nosferatu. Disponível em: <http://www.bocc.ubi.pt/pag/simoespedro-o-eterno-retorno-de-nosferatu.pdf>. Acesso em 19 de março de 2018.

LINDQVIST, John Ajvide. Deixa Ela Entrar. (Trad. Marisol Santos Moreira). São Paulo: Globo, 2012.

MICHAELIS. Dicionário Brasileiro da Língua Portuguesa. Michaelis Online. Editora Melhoramentes, 2016.2 Disponível em: $<\mathrm{http}: / /$ michaelis.uol.com.br/busca? $r=0 \& \mathrm{f}=0 \& \mathrm{t}=0 \&$ palavra=vampiro $>$. Acesso em: 19 de março de 2018.

ROAS, David, A ameaça do fantástico: aproximações teóricas. São Paulo: Unesp, 2014. 215p.

. El monstruo pós-moderno y los limites de lo fantástico. Rio de Janeiro, UERJ, 2014. (Palestra).

STOKER, Bram. Drácula. (Trad. Vera M. Renoldi). São Paulo: Nova Cultural, 2002. 366p.

TODOROV, Tzvetan, Introdução à literatura fantástica. (Trad. Maria Clara Correa Castello). São Paulo: Perspectiva, 2008. 188p.

Data da Submissão: 19/03/2018

Data da Aprovação: 24/07/2018 